\title{
The Diverse Roles of Specific GLP-1 Receptors in the Control of Food Intake and the Response to Visceral Illness
}

\author{
Kimberly P. Kinzig, ${ }^{1}$ David A. D'Alessio, ${ }^{2}$ and Randy J. Seeley ${ }^{1}$ \\ Departments of ${ }^{1}$ Psychiatry and ${ }^{2}$ Medicine, University of Cincinnati College of Medicine, Cincinnati, Ohio 45267-0559
}

Intracerebroventricular administration of glucagon-like peptide-1 (7-36) amide (GLP-1) reduces food intake and produces symptoms of visceral illness, such as a conditioned taste aversion (CTA). The central hypothesis of the present work is that separate populations of GLP-1 receptors mediate the anorexia and taste aversion associated with GLP-1 administration. To test this hypothesis, we first compared the ability of various doses of GLP-1 to induce anorexia or CTA when administered into either the lateral or fourth ventricle. Lateral and fourth ventricular GLP-1 resulted in reduction of food intake at similar doses, whereas only lateral ventricular GLP-1 resulted in a CTA. Such data indicate that both hypothalamic and caudal brainstem GLP-1 receptors are likely to participate in the ability of GLP-1 to reduce food intake. We also hypothesized that the site that must mediate the ability of GLP-1 to induce visceral illness is in the central nucleus of the amygdala (CeA). Administration of 0.2 or $1.0 \mu \mathrm{g}$ of GLP-1 (7-36) but not the inactive GLP-1 (9-36) resulted in a strong CTA with no accompanying anorexia. In addition, bilateral CeA administration of $2.5 \mu \mathrm{g}$ of a GLP-1 receptor antagonist before intraperitoneal administration of the toxin lithium chloride resulted in a diminished CTA. Together, these data indicate that separate GLP-1 receptor populations mediate the multiple responses to GLP-1. These results indicate that GLP-1 is a flexible system that can be activated under various circumstances to alter the ingestion of nutrients and/or produce other visceral illness responses, depending on the ascending pathways of the GLP-1 system that are recruited.

Key words: conditioned taste aversion; GLP-1; food intake; visceral illness; central nucleus of the amygdala; hypothalamus
Glucagon-like peptide-1 (7-36) amide (GLP-1) is a posttranslational product of preproglucagon that is produced in the brainstem (Han et al., 1986; Jin et al., 1988). GLP-1-producing neurons project to a number of brain areas, including the central nucleus of the amygdala (CeA) and the paraventricular nucleus of the hypothalamus (PVN) (Goke et al., 1995), and the GLP-1 receptor (GLP-1r) is located in these regions (Han et al., 1986; Merchenthaler et al., 1999). Intracerebroventricular administration of GLP-1 (Tang-Christensen et al., 1996; Turton et al., 1996; van Dijk et al., 1997) or injection directly into the PVN (McMahon and Wellman, 1997) potently inhibits food intake. Therefore, it has been proposed that GLP-1 has a physiological role in the suppression of food intake.

Although the effect of GLP-1 to cause anorexia is unquestioned, the regulatory system served by GLP-1 is unclear. Some investigators have proposed that GLP-1 has a role in energy balance (Gunn et al., 1996; Turton et al., 1996; Goldstone et al., 1997; Meeran et al., 1999), possibly through interactions with leptin signaling (Goldstone et al., 1997, 2000). However, some evidence indicates that GLP-1 is involved in suppression of food intake through mediating the response to visceral illness (Thiele et al., 1997, 1998; Rinaman 1999b; Seeley et al., 2000). Intracerebroventricular infusion of GLP-1 into the rat produces a conditioned taste aversion (CTA) (Thiele et al., 1997; van Dijk et al., 1997) and increases consumption of nonnutritive clay (Seeley et al., 2000). These effects can be blocked with a GLP-1 receptor

Received July 18, 2002; revised Sept. 18, 2002; accepted Sept. 18, 2002.

This work was supported by National Institutes of Health Grant DK54890 and the Procter and Gamble Company.

Correspondence should be addressed to Kimberly Kinzig, University of Cincinnati, Department of Psychiatry, ML 0559, 231 Albert Sabin Way, Cincinnati, OH 45267-0559. E-mail: kinzigkp@email.uc.edu.

Copyright (C) 2002 Society for Neuroscience $0270-6474 / 02 / 2210470-07 \$ 15.00 / 0$

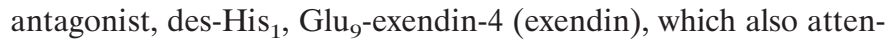
uates much of the illness response to the toxin lithium chloride (LiCl) (Seeley et al., 2000). These and other data (Rinaman 1999a,b; Rinaman and Comer, 2000) suggest that GLP-1 signaling in the CNS is involved in the response to toxins and other illness-inducing stimuli. It is unclear at present whether the effect of GLP-1 to inhibit food intake is part of the system regulating energy balance, the system mediating visceral illness, or both.

Given the limited and focal distribution of GLP-1 neurons in the CNS, it seems likely that the diverse responses mediated by this peptide are a result of projections to specific effector nuclei. This model would provide a potential explanation for the participation of GLP-1 in the control of food intake as it relates to both energy balance and visceral illness. In fact, there is already indirect support for a dissociation of aversive and anorectic effects of GLP-1. McMahon and Wellman (1997) demonstrated a reduction in food intake without a CTA after direct injection of GLP-1 into the PVN, suggesting that signaling through hypothalamic GLP-1 receptors may be independent of the illness response.

The present experiments were undertaken to determine whether different populations of GLP-1 receptors mediate the inhibition of food intake and the behaviors that compose the visceral illness response. We hypothesized that hypothalamic GLP-1 receptors mediate anorexia, whereas extrahypothalamic GLP-1 receptors are responsible for other aspects of the visceral illness response. To test this hypothesis, we compared the relative potency of GLP-1 to reduce food intake and produce a CTA when given into the lateral ventricle, into the fourth ventricle, or directly into the $\mathrm{CeA}$. In addition, we tested the effects of bilateral $\mathrm{CeA}$ administration of exendin on the development of a LiCl-induced CTA. 


\section{MATERIALS AND METHODS}

Experiment 1: food intake and GLP-1 administration in the lateral ventricle. Twenty male Long-Evans rats (300-375 gm) obtained from Charles River Laboratories (Wilmington, MA) were housed individually in standard plastic rodent cages and maintained on a $12 \mathrm{hr}$ light/dark cycle. Under ketamine ( $9 \mathrm{mg} / \mathrm{kg}$, i.p.) and xylazine (1.5 mg/kg, i.p.) anesthesia, rats had 21 gauge stainless steel cannulas (Plastics One, Roanoke, VA) implanted in the lateral ventricle $[-1.8 \mathrm{~mm}$ anteroposterior (AP), -1.6 $\mathrm{mm}$ mediolateral (ML), and $-3.3 \mathrm{~mm}$ dorsoventral (DV) with respect to bregma). The cannulas were fixed to the skull with anchor screws and dental acrylic and fitted with removal obturators that extended $0.5 \mathrm{~mm}$ beyond the tip of the guide cannula. Placement of each lateral ventricle cannula was confirmed by administration of $10 \mathrm{ng}$ of angiotensin II (AII) in $2 \mu \mathrm{l}$ of saline through the cannula, as described previously (Thiele et al., 1998). Rats who failed to drink a minimum of $5 \mathrm{ml}$ in the 60 min after AII treatment were assumed to have misplaced cannulas and were removed from the study $(n=3$ removed).

After a postsurgical recovery time of 2 weeks, rats were weight matched but otherwise divided randomly into three groups $(n=6$ per group in two groups; $n=5$ in the third group). Each rat received three treatments with $4 \mathrm{~d}$ between each treatment. This was a mixed design in which each rat received saline and two of five possible doses of GLP-1 $(0.1,0.3,0.6,1.0$, and $10 \mu \mathrm{g}$ in $2 \mu \mathrm{l}$ of saline) over the course of the experiment. Food was removed from each animal's cage $2 \mathrm{hr}$ before lights off. At $1 \mathrm{hr}$ before lights off, the rats received a lateral ventricular injection of saline or GLP-1 (7-36) amide (American Peptides, Sunnyvale, CA). Food was replaced at lights off and intake measured hourly for $3 \mathrm{hr}$ and at $24 \mathrm{hr}$.

Experiment 2: food intake and GLP-1 administration into the fourth ventricle. Twenty male Long-Evans rats (300-375 gm) were implanted with cannulas directed to the fourth cerebral ventricle, as described above, with the exception of the coordinates (-11.6 mm AP, $0 \mathrm{~mm}$ ML, and $-7.8 \mathrm{~mm} \mathrm{DV}$ with respect to bregma). Cannula placement was verified by administration of $10 \mu \mathrm{g}$ of GLP-1 in $2 \mu \mathrm{l}$ of saline $1 \mathrm{hr}$ before the onset of lights off. Food intake was measured hourly for $3 \mathrm{hr}$ after injection and compared with food intake after injection of $2 \mu \mathrm{l}$ of saline. Rats were included in the study if their $3 \mathrm{hr}$ food intake was suppressed by $50 \%$ or more compared with food intake after saline injection $(n=4$ removed). After completion of the experiments, cannula placement was confirmed by direct examination of the fourth ventricle after injection of $1 \mu \mathrm{l}$ of cresyl violet. All of the rats included in the experiments did, in fact, have cresyl violet limited to the fourth ventricle, indicating that each cannula placement was correct. The design of the experiment was identical to experiment 1 , except that GLP-1 $(0.1,0.3,0.6,1.0$, or $10 \mu \mathrm{g})$ or saline was administered into the fourth ventricle $(n=5$ per group).

Experiment 3: induction of a conditioned taste aversion by central GLP-1. Sixteen of the rats with lateral ventricular cannulas and 16 with fourth ventricular cannulas from experiments 1 and 2 were weight matched and divided such that half of each group ( $n=8$ with lateral ventricular cannulas; $n=8$ with fourth ventricular cannulas) would receive an infusion of $0.6 \mu \mathrm{g}$ of GLP-1 and the other half would receive $1 \mu \mathrm{g}$ of GLP-1 in $2 \mu$ l of saline on the appropriate conditioning day. These doses were chosen because they represented the threshold doses that reliably produced reductions in food intake when administered into the fourth or lateral ventricle, respectively. All animals were trained on a water deprivation schedule during which they were allowed access to two water bottles for $1 \mathrm{hr} / \mathrm{d}$. Intake was measured, and, by day 10, each rat was consistently drinking at least $15 \mathrm{ml} / \mathrm{d}(16.87 \pm 0.64)$ and drinking equivalently from both bottles. Groups were also divided such that half of each group received GLP-1 on conditioning day 1 and half received 2 $\mu \mathrm{l}$ of saline. Instead of water, rats were presented with two bottles of saccharin-sweetened Kool-Aid [flavor 1 (10 ml of saccharin, $3500 \mathrm{ml}$ of water, and one packet cherry or grape Kool-Aid at room temperature; both bottles containing the same flavor, in a counterbalanced manner)]. After access to flavor 1, rats were injected with either saline or their assigned dose of GLP-1. Rats were subsequently given $1 \mathrm{~d}$ of normal $1 \mathrm{hr}$ water access as a rest day. On conditioning day 2 , rats that were injected with GLP-1 were injected with saline and vice versa. For their wateraccess period, they received a second novel flavor (two bottles of the same flavor: cherry or grape). The test day occurred $2 \mathrm{~d}$ later and consisted of $1 \mathrm{hr}$ access to one bottle of each flavor, with the side of flavor presentation being switched at $30 \mathrm{~min}$ to avoid any side preference. Fluid intake was measured at $1 \mathrm{hr}$, and water was replaced at the end of the study.

Experiment 4: food intake and GLP-1 administration in the central nucleus of the amygdala. GLP-1 did not support a conditioned taste aversion when administered into the fourth cerebral ventricle, as we had hypothesized. Although our data demonstrate that lateral ventricular GLP-1 clearly produces a CTA, local injection into the PVN does not (McMahon and Wellman, 1997). One potential explanation for these finding is the possibility that GLP-1 receptors in the CeA might mediate the ability of GLP-1 to produce a taste aversion. To test the hypothesis that GLP-1 receptors in the CeA mediate the ability of GLP-1 to induce anorexia, 20 male Long-Evans rats (300-375 gm) were implanted with cannulas aimed at the CeA $(-2.3 \mathrm{~mm} \mathrm{AP},+4.1 \mathrm{~mm} \mathrm{ML}$, and $-7.4 \mathrm{~mm}$ DV with respect to bregma).

After a postsurgical recovery time of 2 weeks, rats were weight matched and divided into three groups $(n=7$ per group for 2 groups; $n=6$ for the third group). Experimental trials were conducted such that, on every fourth day, rats received saline or a dose of GLP-1 (0.1, 0.2, 0.6, and $1.0 \mu \mathrm{g}$ in $0.5 \mu \mathrm{l}$ of saline), and each rat was exposed to saline plus two of the GLP-1 doses over the course of the experiment. Food was removed from each animal's cage $2 \mathrm{hr}$ before lights off. At $1 \mathrm{hr}$ before lights off, the rats received an intra-amygdalar injection of saline or GLP-1 (7-36) amide. Food was replaced at lights off and measured hourly for $2 \mathrm{hr}$ and at $24 \mathrm{hr}$.

Experiment 5: conditioned taste aversion and GLP-1 (7-36) administration in the central amygdala. To test the hypothesis that GLP-1 receptors in the CeA mediate the ability of GLP-1 to cause a CTA, rats were divided into two groups ( $n=10$ per group) and trained to the waterdeprivation schedule described for experiment 3 . On conditioning day 1 , half of group A received a CeA infusion of $0.2 \mu \mathrm{g}$ of GLP-1 in $0.5 \mu \mathrm{l}$ of saline over $2 \mathrm{~min}$, and the other half received a CeA infusion of $0.5 \mu \mathrm{l}$ of saline over 2 min. Similarly, half of group B received a CeA infusion of $1 \mu \mathrm{g} \mathrm{GLP}-1$ in $0.5 \mu \mathrm{l}$ of saline over $2 \mathrm{~min}$, and the other half received a CeA infusion of $0.5 \mu \mathrm{l}$ of saline. Each rat was given access to two bottles of one Kool-Aid flavor as described above, with the following water-access day. On conditioning day 2 , each rat received a $\mathrm{CeA}$ infusion of either saline or GLP-1 (the opposite of what was inf used on conditioning day 1 ), followed by $1 \mathrm{hr}$ access to the other flavor. This was followed by another water-access day and culminated in a test day, as described in experiment 3 , in which intake of both flavors was recorded.

Cannula placement was verified empirically by cresyl violet injection before perfusion after the completion of the studies. Brains were subsequently sectioned at $50 \mu \mathrm{m}$, and placement was verified (Fig. 1). Any rat whose cannula was not in the $\mathrm{CeA}$ was excluded from the data analyses $(n=5$ removed $)$.

As a negative control, an additional group of rats were implanted with cannulas aimed at the $\mathrm{CeA}(n=20)$ to test whether an alternative peptide, GLP-1 (9-36), would cause a CTA when administered into the CeA. Biologically active GLP-1 (7-36) is cleaved enzymatically to a closely related metabolite, GLP-1 (9-36). GLP-1 (9-36) binds to the GLP-1r with a much lower affinity than does GLP-1 but does not agonize the GLP-1r in vitro or reduce food intake when administered intracerebroventricularly (Montrose-Rafizadeh et al., 1997). Thus, GLP-1 (9-36) is well suited as a control for nonspecific effects of CeA injection of GLP-1 (7-36). The same paradigm as that described for GLP-1 (7-36) was used. One microgram of GLP-1 (9-36) in $0.5 \mu \mathrm{l}$ of saline was paired with one flavor, and $0.5 \mu \mathrm{l}$ of saline was paired with the other.

As described previously, cannula placement was verified by cresyl violet injection before perfusion, and rats whose cannulas were not in the CeA were excluded from the data analyses ( $n=4$ excluded) (Fig. 2).

Experiment 6: the central nucleus of the amygdala, GLP-1 receptor antagonism, and LiCl-induced conditioned taste aversion. To determine the effects of GLP-1 receptor antagonism in the CeA on the development of a CTA, 20 naïve male rats were implanted with bilateral cannulas aimed at the CeA $(-2.3 \mathrm{~mm} \mathrm{AP}, \pm 4.1 \mathrm{~mm} \mathrm{ML}$, and $-7.4 \mathrm{~mm} \mathrm{DV}$ with respect to bregma). After a postoperative recovery time of 2 weeks, rats were trained to consume all of their water from two water bottles in $1 \mathrm{hr}$ ( $23 \mathrm{hr}$ deprivation, $7 \mathrm{~d}$ ), with $\sim 50 \%$ being consumed from each side by day 7. On day 8, rats were divided into two groups on the basis of their average daily water intake. All rats were given $1 \mathrm{hr}$ access to two bottles of a $16 \%$ polycose solution rather than water. Immediately after this hour, rats in one group received bilateral injections of $2.5 \mu \mathrm{g} / 0.5 \mu \mathrm{l}$ of the GLP-1r antagonist exendin. The other group was injected bilaterally with $0.5 \mu \mathrm{l}$ of saline. Fifteen minutes after intra-amygdalar injection, all rats received an injection of $0.15 \mathrm{M} \mathrm{LiCl}$ intraperitoneally, equivalent to $2 \%$ of their body weight. This was followed by $23 \mathrm{hr}$ of water deprivation and $1 \mathrm{hr}$ access to two bottles of water. The test day was preceded by $23 \mathrm{hr}$ of water deprivation and culminated in $1.5 \mathrm{hr}$ access to one bottle of $16 \%$ 


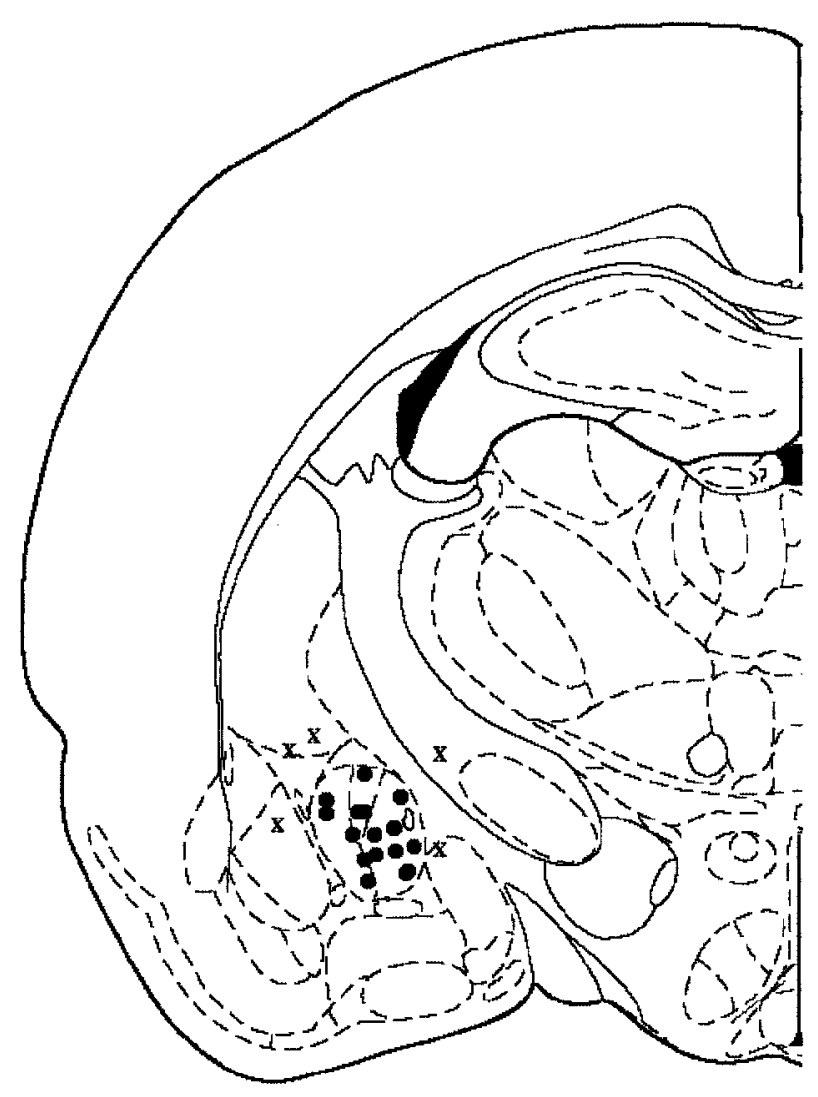

Figure 1. Diagram demonstrating injection sites for all rats used within GLP-1 (7-36) experiments 4 and 5. Black dots represent injection sites within the $\mathrm{CeA}$ for animals whose data were used in analyses; $X$ symbols indicate missed injection sites of animals whose data were excluded from data analyses (adapted from Paxinos and Watson, 1997).

polycose and one bottle of water. Although this polycose protocol differs from that used in the previous experiments, it has been validated previously (Nissenbaum and Sclafani, 1987; Sclafani, 1991; Azzara and Sclafani, 1998; Perez et al., 1999). This paradigm lessened the temporal issues involved in bilateral intra-amygdalar injections followed by intraperitoneal injections in a large group of rats.

At the end of this experiment, cannula placement was verified (Fig. 3) as described previously for unilateral CeA cannulas. Any rat whose cannulas were not placed correctly was excluded from the data analyses $(n=7$ removed $)$.

Data analysis. Comparisons of food intake among the various doses of GLP-1 were made using one-way ANOVA. The intake of flavored drinks in the lateral and fourth ventricular conditioned taste aversion experiments was compared using a three-way ANOVA to determine the effect of dose, followed by a one-way ANOVA to determine the effect of ventricle regardless of the dose of GLP- 1 administered. Fluid intake in the CeA CTA (unilateral and bilateral) experiments was analyzed by Student's $t$ test. All data are presented as the mean \pm SEM.

\section{RESULTS}

\section{Experiment 1: food intake and GLP-1 administration in the lateral ventricle}

Administration of GLP-1 in the lateral ventricle caused a dosedependent decrease in food intake (Fig. 4). Administration of both 1.0 and $10.0 \mu \mathrm{g}$ of GLP-1 significantly decreased food intake for $2 \mathrm{hr}\left(F_{(1,17)}=6.22, p<0.05\right.$ and $F_{(1,17)}=10.94, p<0.05$, respectively) and at 1 and $3 \mathrm{hr}$ (data not shown) after the onset of the dark cycle. As has been reported previously, this effect waned

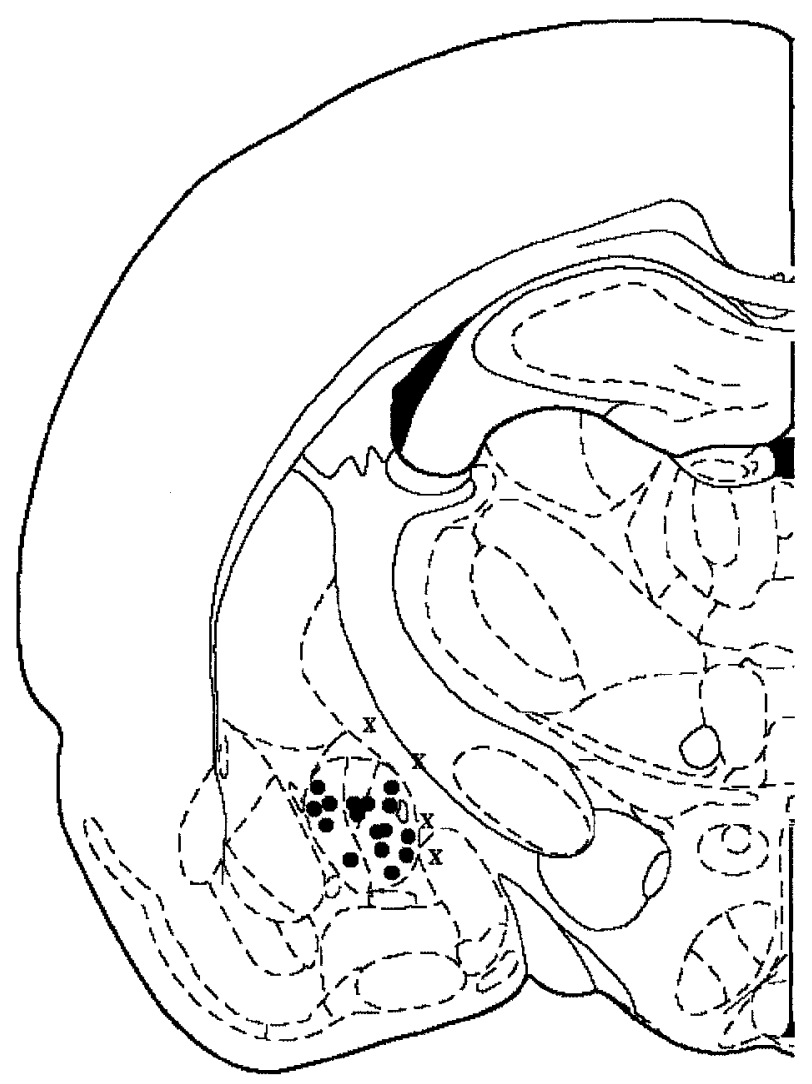

Figure 2. Diagram demonstrating injection sites for all rats used with GLP-1 (9-36) CTA in experiment 5. Black dots represent injection sites within the $\mathrm{CeA}$ for animals whose data were used in analyses; $X$ symbols indicate missed injection sites of animals whose data were excluded from data analyses (adapted from Paxinos and Watson, 1997).

over time, so that there was no significant effect of GLP-1 on food intake at $24 \mathrm{hr}$ (Donahey et al., 1998).

\section{Experiment 2: food intake and GLP-1 administration in the fourth ventricle}

Administration of GLP-1 into the fourth cerebral ventricle also suppressed food intake. Figure 5 shows significant suppression of food intake after fourth ventricular administration of $0.6 \mu \mathrm{g}$ $\left(F_{(1,26)}=4.53 ; p<0.05\right), 1.0 \mu \mathrm{g}\left(F_{(1,26)}=5.73 ; p<0.05\right)$, and 10 $\mu \mathrm{g}\left(F_{(1,26)}=66.17 ; p<0.001\right)$ GLP-1 for $2 \mathrm{hr}$ after the onset of the dark cycle, with a continued suppression for $3 \mathrm{hr}$ with the 1.0 and $10 \mu \mathrm{g}$ doses. Similar to lateral ventricular administration, there was no effect of fourth ventricular GLP-1 to inhibit food intake over the $24 \mathrm{hr}$ of observation.

\section{Experiment 3: GLP-1, the lateral and fourth ventricles, and conditioned taste aversion}

Rats developed a conditioned taste aversion to a novel flavor paired with $0.6 \mu \mathrm{g}$ of GLP-1 $(p<0.05)$ and $1.0 \mu \mathrm{g}$ of GLP-1 $(p<0.05)$ when infused into the lateral ventricle. However, the GLP-1 pairing had no significant effect on flavor intake for either of the doses of GLP-1 when administered into the fourth ventricle. As determined by three-way ANOVA, there was no significant effect of the dose of GLP-1; therefore, that factor was eliminated from the analyses, and a one-way ANOVA was conducted to determine whether the ventricle into which GLP-1 was 


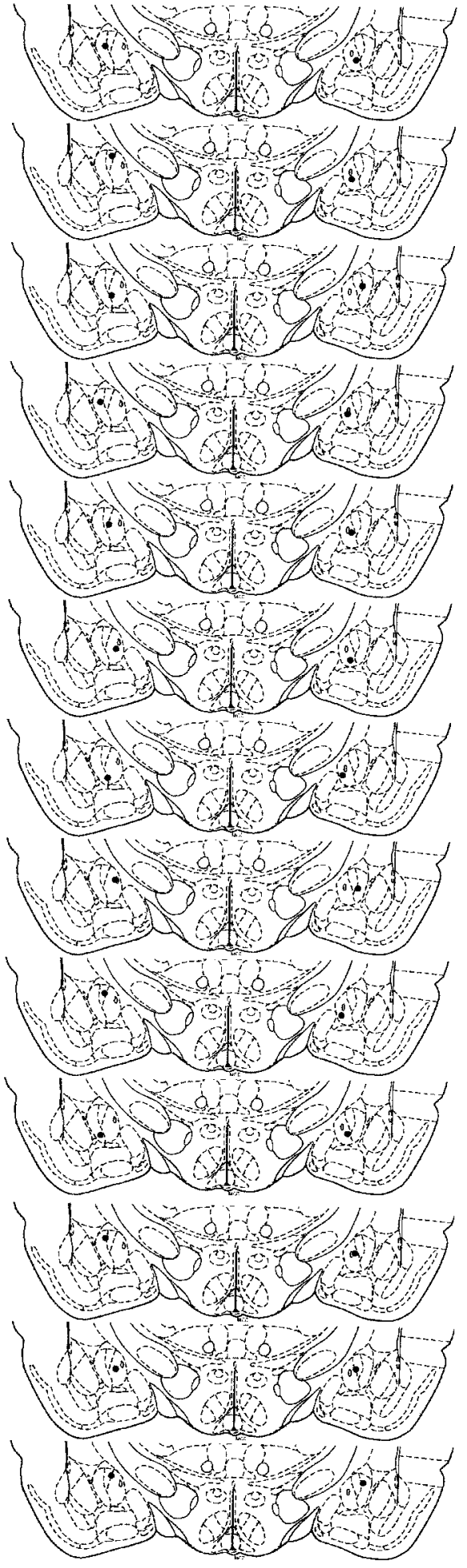

Figure 3. Diagram demonstrating injection sites for bilaterally cannulated rats in experiment 6 . Bilateral injection sites within the $\mathrm{CeA}$ are shown for each of the 13 animals included in data analyses. An additional seven animals had either unilateral or bilateral missed injection sites and were excluded (diagrams not shown) (adapted from Paxinos and Watson, 1997).

infused had a main effect on the development of a CTA after pairing of GLP-1 with a novel flavor. As shown in Figure 6, $A$ and $B$, there was, in fact, a main effect of ventricle on the development of a $\operatorname{CTA}\left(F_{(1,18)}=9.10 ; p<0.01\right)$.

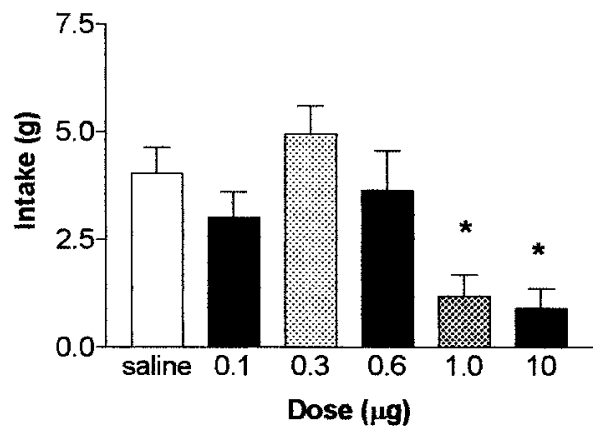

Figure 4. Cumulative $2 \mathrm{hr}$ food intake (mean \pm SEM) after lateral ventricular administration of GLP-1. ${ }^{*} p<0.05$, significantly different from saline.

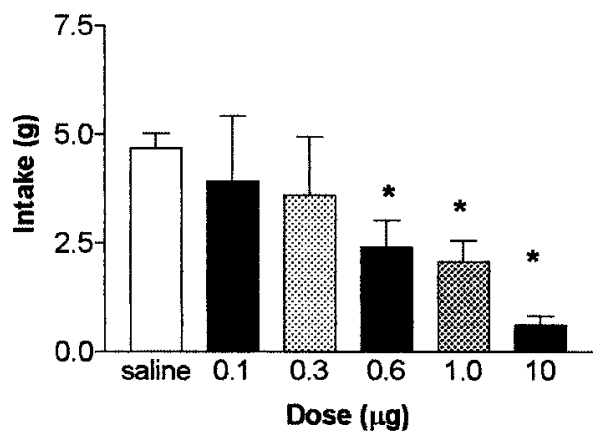

Figure 5. Cumulative $2 \mathrm{hr}$ food intake (mean \pm SEM) after fourth ventricular administration of GLP-1. ${ }^{*} p<0.05$, significantly different from saline.
$\mathbf{A}$

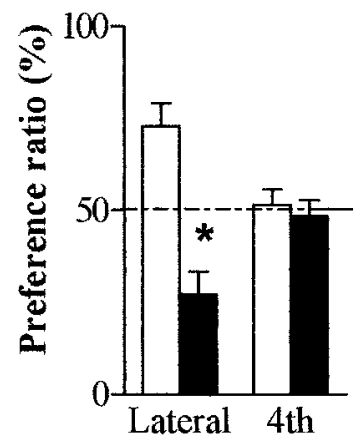

B

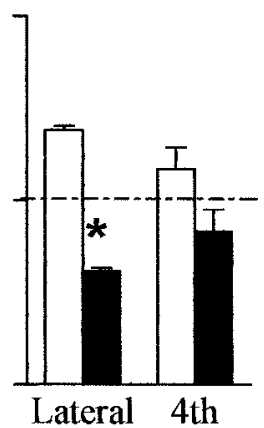

\section{VENTRICLE}

Figure 6. Preference ratios for novel flavor after pairing with saline or GLP-1 in the lateral versus fourth ventricle. Open bars represent intake of saline-paired flavor, and filled bars represent intake of GLP-1-paired flavor. $A$, Preference ratio for a novel flavor when paired with saline or 0.6 $\mu \mathrm{g}$ of GLP-1. $B$, Preference ratio for a novel flavor when paired with saline or $1.0 \mu \mathrm{g}$ of GLP-1. Dashed lines represent expected ratio with no effect of treatment $(50 \%)$. ${ }^{*} p<0.05$, significantly different from salinepaired flavor intake.

\section{Experiment 4: food intake and GLP-1 administration in the central nucleus of the amygdala}

In contrast to the studies in which GLP-1 was infused into either the lateral or fourth ventricle, GLP-1 did not suppress food intake when infused into the CeA at any dose, as shown in Figure 7. 


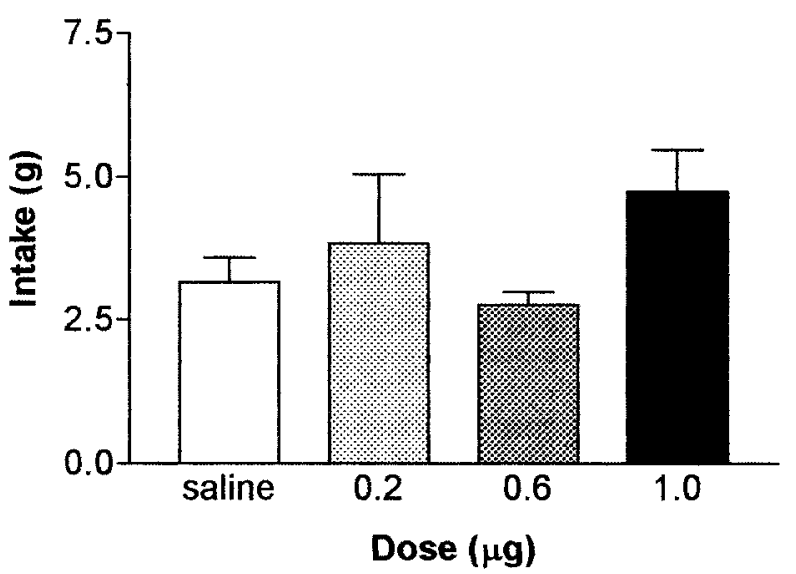

Figure 7. Cumulative $2 \mathrm{hr}$ food intake (mean \pm SEM) after intra-CeA administration of GLP-1 (9-36).

\section{Experiment 5: conditioned taste aversion and GLP-1 administration in the central nucleus of the amygdala}

Data for experiment 5 were analyzed by Student's $t$ test to determine whether there was a significant difference in the preference ratio for the flavor paired with saline compared with the flavor paired with GLP-1. After paired infusion of 0.2 or $1.0 \mu \mathrm{g}$ of GLP-1 into the CeA, there was a significant preference for the flavor that had been paired with saline compared with the GLP1-paired flavor $\left(t_{(6)}=3.5, p<0.05\right.$ and $t_{(7)}=25.54, p<0.01$, respectively). Fluid intake in the $1 \mathrm{hr}$ test period of the animals that received saline and $0.2 \mu \mathrm{g}$ of GLP-1 consisted of $9.22 \pm 0.49$ $\mathrm{ml}$ of the saline-paired flavor compared with $5.78 \pm 1.6 \mathrm{ml}$ of the GLP-1-paired flavor. Fluid intake by the animals in the group that received saline and $1.0 \mu \mathrm{g}$ of GLP-1 consisted of $9.21 \pm 0.67$ $\mathrm{ml}$ of the saline-paired flavor and $5.45 \pm 0.98 \mathrm{ml}$ of the GLP-1paired flavor. There was no development of a CTA in the rats that received $1.0 \mu \mathrm{g}$ of GLP-1 (9-36) into the CeA $\left(t_{(14)}=\right.$ $-0.393 ; p=0.702)$, indicating that the effect seen with GLP-1 was a result of specific activation of the GLP-1r (mean intake of $8.61 \pm 1.96 \mathrm{ml}$ of the saline-paired flavor compared with $8.01 \pm$ $1.36 \mathrm{ml}$ of the GLP-1-paired flavor).

\section{Experiment 6: conditioned taste aversion and bilateral antagonism of GLP-1 receptors in the central nucleus of the amygdala}

Data for experiment 6 were analyzed by Student's $t$ test to determine whether there was a significant difference in the consumption of $16 \%$ polycose after exendin plus $\mathrm{LiCl}$ compared with saline plus $\mathrm{LiCl}$. Rats that received exendin before $\mathrm{LiCl}$ injection consumed significantly more polycose in the $1.5 \mathrm{hr}$ test period than did rats that received saline before $\mathrm{LiCl}(8.62 \pm 1.4$ vs $5.91 \pm$ $\left.0.38 \mathrm{ml} ; t_{(11)}=3.02 ; p<0.05\right)$, indicating attenuation of toxininduced aversiveness learning by GLP-1r blockade.

\section{DISCUSSION}

The physiological role of central GLP-1 as it relates to food intake is controversial. GLP-1 clearly reduces food intake when administered into the third cerebral ventricle at a dose of $3 \mu \mathrm{g}$ (Turton et al., 1996; van Dijk et al., 1997), and some data support a role in energy balance. However, the reduction in food intake after central GLP-1 administration is accompanied by a CTA (Thiele et al., 1997; van Dijk et al., 1997), and the dose-response curves for these effects overlap (van Dijk et al., 1997), raising the possibility that GLP-1-induced anorexia is simply secondary to visceral illness. The results of the present study demonstrate that anorexia and CTA resulting from central GLP-1 signaling are mediated at distinct sites and provide direct evidence that the actions of GLP-1 to alter food intake and produce visceral illness are dissociable.

The effect of GLP-1 to reduce food intake is present whether the peptide is administered into the lateral ventricle (TangChristensen et al., 1996), the third ventricle (Turton et al., 1996; van Dijk et al., 1997), or the PVN (McMahon and Wellman, 1997). Peptides delivered to these sites have access to major accumulations of GLP-1r in the brainstem, hypothalamus, and $\mathrm{CeA}$. We increased the understanding of the functional neuroanatomy of the central GLP-1 system by demonstrating that GLP-1 given into the fourth ventricle suppresses food intake, whereas direct $\mathrm{CeA}$ administration does not. Given the rostralto-caudal flow of CSF, our findings suggest at least two brain centers, the PVN and the brainstem, in which GLP-1-induced anorexia is mediated. The specificity of action is demonstrated by the absence of an effect of direct injection of peptide into the $\mathrm{CeA}$ and suggests that anorexia after lateral ventricular GLP-1 is mediated downstream.

Work by others had demonstrated that no CTA is associated with GLP-1 administration in the lateral ventricle at doses that induce anorexia (Tang-Christensen et al., 1996). However, using a different and possibly more sensitive method by which to measure a CTA, we found the opposite to be true. Not only did we observe a CTA when a novel flavor was paired with GLP-1 administration in the lateral ventricle, but we also did so at a dose lower than that required in the third ventricle and lower than that required to reduce food intake in the lateral ventricle $(0.6 \mu \mathrm{g}$ to induce a CTA compared with $1.0 \mu \mathrm{g}$ to reduce food intake in the lateral ventricle). Together with the data from the third ventricle, we hypothesized that separate populations of GLP-1 receptors mediate the anorexic as opposed to the visceral illness effects of GLP-1.

Several lines of evidence implicate the caudal brainstem in mediating the action of GLP-1. GLP-1 is synthesized in neurons in the region of the nucleus of the solitary tract (NTS) and the area postrema of the brainstem, and receptors for GLP-1 are found in both the NTS and the area postrema (Han et al., 1986; Jin et al., 1988; Drucker, 1990). These brainstem areas have long been associated with illness produced by $\mathrm{LiCl}$ (Bernstein et al., 1992; Houpt et al., 1994; Thiele et al., 1996). Given that intraperitoneal $\mathrm{LiCl}$ and third ventricular GLP-1 both produce a similar pattern of neuronal activation (van Dijk et al., 1996; Thiele et al., 1998), including the NTS, and that both lateral and third ventricular administration of peptides have been demonstrated to activate brainstem receptors, we reasoned that it was possible that brainstem GLP-1 receptors were responsible for the visceral illness effects of GLP-1 in either the lateral or third ventricle.

To our surprise, fourth ventricular administration of GLP-1 reduced food intake at a lower dose than that required in the lateral ventricle ( $0.6 \mathrm{vs} 1 \mu \mathrm{g})$ (Figs. 4,5$)$. However, there was no CTA development after the pairing of a novel flavor to this dose or even a higher dose. These data make two important points. First, it would seem that, in addition to hypothalamic receptors in the region of the PVN, activation of brainstem GLP-1 receptors produces potent reductions in food intake that are not secondary to responses to illness. Second, because fourth ventricular administration of GLP-1 does not produce a CTA, it is unlikely that 
brainstem receptors mediate the potent actions of GLP-1 to produce symptoms of visceral illness. This is surprising, given several lines of evidence that implicate caudal brainstem structures as being critical in the response to visceral illness (Stricker and Verbalis, 1991).

It is important to note that a major assumption in the experiments in which GLP-1 is delivered intracerebroventricularly is that the peptide is accessing cognate receptors. A great deal of evidence suggests that proteins delivered intracerebroventricularly exert their effects at tissue proximal to the ventricular lining, at the pial surface of the brain, and/or peripherally, as CSF rapidly moves solutes from the ventricular system to the systemic circulation (Fenstermacher and Kaye, 1988; Prokai, 1988; Pardridge, 1992, 1997). Bittencourt and Sawchenko (2002) demonstrated clearly, however, that neuropeptides do access cognate receptors, regardless of the distance from injection site. Although this adds validity to the approach of determining the central effects of GLP-1 via intracerebroventricular injection, this approach leaves unanswered the question of specificity of the site of action. GLP-1 administered in the third and lateral ventricles causes a CTA. GLP-1 in the fourth ventricle reduces food intake without causing a CTA. As informative as these data are, they only provide a clue as to the actual site mediating the CTA. Direct injection into specific nuclei provides a much more definitive answer as to the mediation of the GLP1-induced CTA.

In addition to the PVN, NTS, and area postrema, GLP-1 receptors are also found prominently in the $\mathrm{CeA}$. Several lines of evidence implicate the $\mathrm{CeA}$ in taste aversion learning (Lasiter and Glanzman, 1985; Lamprecht et al., 1997). Moreover, both $\mathrm{LiCl}$ and GLP-1 produce significant neuronal activation in the CeA. Thus, we hypothesized that GLP-1 receptors in the CeA could mediate the ability of GLP-1 to induce a CTA. In contrast to the results in the lateral, third, or fourth ventricle, none of the GLP-1 doses tested in the CeA produced any reductions in food intake. However, those same doses were highly effective at producing a CTA. These results are consistent with the hypothesis that GLP-1 receptors within the CeA are responsible for the visceral illness symptoms observed after lateral ventricular administration of GLP-1. In addition, GLP-1 receptor antagonism in the $\mathrm{CeA}$ before $\mathrm{LiCl}$ injection resulted in a significant increase in the consumption of the novel flavor that was paired with $\mathrm{LiCl}$. These data support the view that GLP-1- and LiCl-induced CTAs are mediated specifically by the GLP-1 receptor populations in the CeA.

This hypothesis is consistent with several other pieces of data. First, the ability of lateral but not fourth ventricular GLP-1 to produce a CTA is explained by the rostral-to-caudal flow of the CSF, which would not allow fourth ventricular GLP-1 to reach the critical receptors in the CeA, whereas the much closer proximity of the lateral ventricles would allow for CeA activation. Similarly, local application of low doses of GLP-1 into the PVN results in reductions in food intake without an evident CTA (McMahon and Wellman, 1997). Finally, $10 \mu \mathrm{g}$ of the potent GLP-1 receptor antagonist des-His ${ }_{1}, \mathrm{Glu}_{9}$-exendin-4 into the third ventricle can block the anorexic effect of $10 \mu \mathrm{g}$ of GLP-1, whereas $50 \mu \mathrm{g}$ of the same antagonist is necessary to block the CTA produced by intraperitoneal LiCl (Seeley et al., 2000). The present data would indicate that the high dose of the antagonist is necessary because the antagonist must attain sufficient concentrations to block endogenous GLP-1 released in the CeA.

On the basis of the results of this study, we propose that the anorectic actions of GLP-1 are mediated in brainstem and hypothalamic nuclei, whereas the aversive responses are signaled via receptors in the $\mathrm{CeA}$. The present experiments shed considerable light on the organization of the central GLP-1 system. GLP-1 receptors both in the caudal brainstem and within the hypothalamus seem to be linked directly to the control of food intake, whereas GLP-1 receptors within the CeA seem to be linked to other neurally mediated responses to visceral illness, such as CTA. Thus, when LiCl, high doses of cholecystokinin, or lipopolysaccharide activate GLP-1 neurons in the NTS (Rinaman, 1999a), it most likely activates projections to both the PVN (or potentially within the NTS) and the CeA, resulting in both anorexia and visceral illness. However, under other circumstances, GLP-1-producing neurons that do not project to the CeA could be recruited to produce reductions in food intake without concomitant visceral illness. The picture that emerges is one of the GLP-1 system as a critical but flexible mediator of interoceptive information from the brainstem to different limbic structures, eliciting distinct responses based on specific input.

\section{REFERENCES}

Azzara AV, Sclafani A (1998) Flavor preferences conditioned by intragastric sugar inf usions in rats: maltose is more reinforcing than sucrose. Physiol Behav 64:535-541.

Bernstein IL, Chavez M, Allen D, Taylor EM (1992) Area postrema mediation of physiological and behavioral effects of lithium chloride in the rat. Brain Res 575:132-137.

Bittencourt JC, Sawchenko PE (2000) Do centrally administered neuropeptides access cognate receptors? An analysis in the central corticotropin-releasing factor system. J Neurosci 20:1142-1156.

Donahey JCK, van Dijk G, Woods SC, Seeley RJ (1998) Intraventricular GLP-1 reduces short- but not long-term food intake or body weight in lean and obese rats. Brain Res 779:75-83.

Drucker DJ (1990) Glucagon and the glucagon-like peptides. Pancreas 5:484-488.

Fenstermacher J, Kaye T (1988) Drug "diffusion" within the brain. Ann NY Acad Sci 531:29-39.

Goke R, Larsen PJ, Mikkelson JD, Sheikh SP (1995) Distribution of GLP-1 binding sites in the rat brain: evidence that exendin is a ligand of brain GLP-1 sites. Eur J Neurosci 7:2294-2300.

Goldstone AP, Mercer JG, Gunn I, Moar KM, Edwards CM, Rossi M, Howard JK, Rasheed S, Turton MD, Small C, Heath MM, O'Shea D, Sterre J, Meeran K, Ghatei MA, Hoggard N, Bloom SR (1997) Leptin interacts with glucagon-like peptide-1 neurons to reduce food intake and body weight in rodents. FEBS Lett 415:134-138.

Goldstone AP, Morgan I, Mercer JG, Morgan JG, Moar KM, Ghatei MA, Bloom SR (2000) Effect of leptin on hypothalamic GLP-1 peptide and brain-stem preproglucagon mRNA. Biochem Biophys Res Commun 269:331-335.

Gunn I, O'Shea D, Turton MD, Beak SA, Bloom SR (1996) Central glucagon-like peptide-1 in the control of feeding. Biochem Soc Trans 24:581-584

Han VK, Hynes MA, Jin C, Towle AC, Lauder JM, Lund PK (1986) Cellular localization of proglucagon/glucagon-like peptide 1 messenger RNAs in rat brain. J Neurosci Res 16:97-107.

Houpt TA, Philopena JM, Wessel TC, Joh TH, Smith GP (1994) Increased c-Fos expression in the nucleus of the solitary tract correlated with conditioned taste aversion to sucrose in rats. Neurosci Lett 172:1-5.

Jin SL, Han VK, Simmons JG, Towle AC, Lauder JM, Lund PK (1988) Distribution of glucagon-like peptide1 (GLP-1), glucagon, and glicentin in the rat brain: an immunocytochemical study. J Comp Neurol 271:519-532.

Lamprecht R, Hazvi S, Dudai Y (1997) cAMP response elementbinding protein in the amygdala is required for long- but not short-term conditioned taste aversion memory. J Neurosci 17:8443-8450.

Lasiter PS, Glanzman DL (1985) Cortical substrates of taste aversion learning: involvement of dorsolateral amygdaloid nuclei and temporal neocortex in taste aversion learning. Behav Neurosci 99:257-276.

McMahon LR, Wellman PJ (1997) PVN infusion of GLP-1 (7-36) amide suppresses feeding and drinking but does not induce conditioned taste aversions or alter locomotion in rats. Am J Physiol 274:R23-R29. Meeran K, O'Shea D, Edwards CM, Turton MD, Heath MM, Gunn I, Abusnan S, Rossi M, Small CJ, Goldstone AP, Taylor GM, Sunter D, Steere J, Choi SJ, Ghatei MA, Bloom SR (1999) Repeated intracerebroventricular administration of glucagon-like peptide-1-(7-36) amide 
or exendin-(9-39) alters body weight in the rat. Endocrinology 140:244-250.

Merchenthaler I, Lane M, Shughrue P (1999) Distribution of preproglucagon and glucagon-like peptide-1 receptor mRNAs in the rat central nervous system. J Comp Neurol 403:261-280.

Montrose-Rafizadeh C, Yang H, Wang Y, Roth J, Montrose MH, Adams LG (1997) Novel signal transduction and peptide specificity of glucagon-like peptide receptor in 3T3-L1 adipocytes. J Cell Physiol 172:275-283.

Nissenbaum JW, Sclafani A (1987) Qualitative differences in polysaccharide and sugar tastes in the rat: a two-carbohydrate taste model. Neurosci Biobehav Rev 11:187-196.

Pardridge WM (1992) Recent developments in peptide delivery to the brain. Pharmacol Toxicol 71:3-10.

Pardridge WM (1997) Drug delivery to the brain. J Cereb Blood Flow Metab 7:713-731.

Paxinos G, Watson C (1997) The rat brain in stereotaxic coordinates, Ed 3. New York: Academic.

Perez C, Fanizza LJ, Sclafani A (1999) Flavor preferences conditioned by intragastric nutrient infusions in rats fed chow or cafeteria diet. Appetite 32:155-170.

Prokai L (1988) Peptide drug delivery into the central nervous system. Prog Drug Res 51:95-131.

Rinaman L (1999a) Interoceptive stress activates glucagon-like peptide-1 neurons that project to the hypothalamus. Am J Physiol 277:R582-R590.

Rinaman L (1999b) A functional role for central glucagon-like peptide-1 receptors in lithium chloride-induced anorexia. Am J Physiol 277:R1537-R1540.

Rinaman L, Comer J (2000) Antagonism of central glucagon-like peptide-1 receptors enhances lipopolysaccharide-induced fever. Auton Neurosci 85:98-101.

Sclafani A (1991) Starch and sugar tastes in rodents: an update. Brain Res Bull 27:383-386.
Seeley RJ, Blake K, Rushing PA, Benoit S, Eng J, Woods SC, D'Alessio D (2000) The role of CNS glucagon-like-peptide-1 (7-36) amide receptors in mediating the visceral illness effects of lithium chloride. J Neurosci 20:1616-1621.

Stricker EM, Verbalis JG (1991) Caloric and noncaloric controls of food intake. Brain Res Bull 27:299-303.

Tang-Christensen M, Larsen PJ, Goke R, Fink-Jensen A, Jessop DS, Moller M, Sheikh SP (1996) Central administration of GLP-1 (7-36) amide inhibits food and water intake in rats. Am J Physiol 271:R848-R856.

Thiele TE, Roitman MF, Bernstein IL (1996) c-Fos induction in the rat brainstem in response to ethanol- and lithium chloride-induced taste aversions. Alcohol Clin Exp Res 20:1023-1028.

Thiele TE, van Dijk G, Campfield LA, Smith FJ, Burn P, Woods SC, Bernstein IL, Seeley RJ (1997) Central administration of GLP-1, but not leptin, produces conditioned taste aversions in the rat. Am J Physiol 272:R726-R730.

Thiele TE, Seeley RJ, D'Alessio D, Eng J, Woods SC, Bernstein IL (1998) Central infusion of GLP-1(7-36) amide receptor antagonist attenuates lithium chloride-induced c-Fos induction in rat brainstem. Brain Res 801:164-170.

Turton MD, O’Shea D, Gunn I, Beak SA, Edwards CMB, Meeran K, Choi SJ, Taylor GM, Heath MM, Lambert PD, Wilding JPH, Smith DH, Ghatei MA, Herbert J, Bloom SR (1996) A role for glucagon-like peptide-1 in the central regulation of feeding. Nature 379:69-72.

van Dijk G, Thiele TE, Donahey JCK, Campfield LA, Smith FJ, Burn P, Bernstein IL, Woods SC, Seeley RJ (1996) Central infusion of leptin and GLP-1 (7-36) amide differentially stimulate c-Fos-like immunoreactivity in the rat brain. Am J Physiol 271:R1096-R1100.

van Dijk G, Thiele TE, Seeley RJ, Woods SC, Bernstein IL (1997) Glucagon-like peptide-1 and satiety. Nature 385:214. 